\title{
Effectiveness of therapy with basal insulin analogs to improve glycemic control in type 2 diabetes mellitus patients poorly controlled with oral antidiabetic drugs in combination or not with NPH insulin
}

\author{
Alfonso Soto-González ${ }^{1 \dagger}$ and Diego Bellido-Guerrero ${ }^{2+*}$ \\ *Correspondence: diegobellido@endofer.com \\ ${ }^{\dagger}$ Both authors contributed equally to this work. \\ 'Department of Endocrinology, Complejo Hospitalario Universitario de A Coruña, As Xubias, 84 15006, A Coruña, Spain. \\ ${ }^{2}$ Department of Endocrinology, Hospital Arquitecto Marcide, Carretera San Pedro de Leixa, s/n, 15405, Ferrol (A Coruña), Spain.
}

\begin{abstract}
Objective: To determine the effectiveness of therapy with basal insulin analogs administered in poorly controlled type 2 diabetes mellitus patients switching from oral antidiabetic drugs with or without NPH insulin.

Patients and methods: Observational retrospective study carried out in 250 type 2 diabetes mellitus patients who switched from oral antidiabetic drugs with or without insulin NPH to basal insulin analog, due to poor metabolic control (HbA1c $>8 \%$ ). Demographic data, anthropometric, laboratory parameters and treatment-related information were retrospectively extracted from patients' medical notes at the initiation of therapy with basal insulin analog and after at least 5 months of treatment.

Results: A significant reduction in HbAlc levels between baseline and month $5(9.2 \pm 1.4 \%$ vs $7.6 \pm 1.1 \%$; $<<0.001)$ was obtained, with a total of $61(24.4 \%)$ patients reaching metabolic control (HbAlc $<7 \%)$. An overall non-significant change in body weight was observed between baseline to month $5(79.8 \pm 13.2 \mathrm{~kg}$ vs $79.5 \pm 13.1 \mathrm{~kg} ; \mathrm{p}>0.05)$. Among those 38 subjects who received NPH insulin prior to basal insulin analog, a significant decrease in the number of patients with hypoglycemic episodes after at least 5 months of treatment was seen ( 16 vs 5 ; $\mathrm{p}<0.01)$.

Conclusions: Treatment with long-acting basal insulin analogs improved glycemic control in type 2 diabetes mellitus patients poorly controlled with oral antidiabetic drugs in combination or not with NPH insulin. Moreover, this improvement was produced with a significant reduction in the number of symptomatic hypoglycemic episodes and without a significant increase in body weight.
\end{abstract}

Keywords: Diabetes mellitus, type 2, insulin, long-acting, insulin, NPH

\section{Introduction}

Type 2 diabetes mellitus (T2DM) is a disease characterized by chronic hyperglycemia secondary to a dual pathological mechanism: resistance to the action of insulin and a progressive failure in pancreatic secretion of insulin [1].

For successful management of the disease, it is essential to achieve good metabolic control, based primarily on obtaining near normal glycated hemoglobin ( $\mathrm{HbA1c}$ ) levels. In this context, current guidelines generally recommend achieving and maintaining $\mathrm{HbA} 1 \mathrm{c}$ levels below $7 \%$. However, on an individualized basis according to the characteristics of each patient, $\mathrm{HbA} 1 \mathrm{c}$ levels below $6 \%$ may be considered, as long as the risk of hypoglycemic episodes is not substantially increased $[2,3]$. In this regard, it is well established that the risk of long-term microvascular and macrovascular complications is related to glycaemia control, as measured by HbA1c levels [4]. The results of prospective observational studies have shown that improved metabolic control of diabetes is associated with lower rates of suffering long-term vascular complications $[5,6]$.
Although treatment with oral antidiabetic drugs (OADs), either as sole or combined therapy, is initially effective, it usually proves inadequate as the disease progresses [7]. Progressive impairment of pancreatic beta cells makes it necessary to administer insulin to restore normoglycemia. In this regard, a number of studies have shown that patients with T2DM with inadequate glycemic control after treatment with OADs alone could achieve $\mathrm{HbA} 1 \mathrm{c}$ levels $\leq 7 \%$ by the addition of basal insulin analogs [8-12]. However, in patients with diabetes of long duration, it is common not to use basal insulin early or intensely enough to reach the therapeutic targets necessary to prevent chronic complications. The reasons generally given in these circumstances are doubts about the effectiveness of insulin therapy in patients with T2DM [13] and the fear of suffering hypoglycemic episodes [14].

The aim of this study was to determine the effectiveness of therapy with basal insulin analogs to improve glycemic control in T2DM patients poorly controlled with OADs in combination or not with NPH insulin. 
Soto-González et al. Journal of Diabetes Research \& Clinical Metabolism 2013, http://www.hoajonline.com/journals/pdf/2050-0866-2-20.pdf

Table 1. Baseline characteristics $(\mathrm{N}=250)$.

\begin{tabular}{|c|c|}
\hline Characteristics & Values \\
\hline Age $^{\mathbf{a}}$, years (mean \pm S.D. $)$ & $66.5 \pm 10.9$ \\
\hline \multicolumn{2}{|l|}{ Gender ${ }^{\mathrm{b}}, \mathrm{n}(\%)$} \\
\hline Male & $127(51)$ \\
\hline Female & $122(49)$ \\
\hline Body weight ${ }^{c}, \operatorname{kg}($ mean \pm S.D.) & $79.6 \pm 13.2$ \\
\hline Abdominal circumference ${ }^{\mathrm{d}}, \mathrm{cm}($ mean \pm S.D. $)$ & $101 \pm 14.2$ \\
\hline BMI, $\mathrm{kg} / \mathrm{m}^{2}($ mean \pm S.D. $)$ & $29.9 \pm 4.8$ \\
\hline Disease evolution $^{e}$, years (mean \pm S.D.) & $10.6 \pm 7.4$ \\
\hline Fasting blood glucose, $\mathrm{mmol} / \mathrm{l}$ (mean \pm S.D.) & $11.1 \pm 3.5$ \\
\hline HbAlc, $\%($ mean \pm S.D. $)$ & $9.2 \pm 1.4$ \\
\hline \multicolumn{2}{|l|}{ Comorbidities $^{*}, \mathbf{n}(\%)$} \\
\hline Dyslipidemia & $174(69.3)$ \\
\hline Hypertension & $173(68.9)$ \\
\hline Abdominal obesity & $138(55.0)$ \\
\hline Smoker & $35(14.6)$ \\
\hline \multicolumn{2}{|l|}{ Diabetes complications ${ }^{*}, \mathrm{n}(\%)$} \\
\hline Microalbuminuria & $89(35.5)$ \\
\hline Macroalbuminuria & $15(6.0)$ \\
\hline Retinopathy & $45(17.9)$ \\
\hline Neuropathy & $19(7.6)$ \\
\hline Myocardial infarction & $14(5.6)$ \\
\hline Angina & $16(6.4)$ \\
\hline Unstable angina & $3(1.2)$ \\
\hline Heart failure & $11(4.4)$ \\
\hline Cerebrovascular accident & $10(4.0)$ \\
\hline Transient ischemic accident & $10(4.0)$ \\
\hline Peripheral vascular disease & $39(15.5)$ \\
\hline
\end{tabular}

Missing data: ${ }^{a} n=5,{ }^{b} n=1,{ }^{c} n=6,{ }^{d} n=61,{ }^{e} n=8,{ }^{f} n=10$.

${ }^{*}$ Multiple-choice question. HbA1c, glycated hemoglobin;

BMI, body mass index; S.D., standard deviation.

\section{Patients and methods}

A multicenter, retrospective, epidemiological observation study was carried out at 32 primary care centers from the Spanish Galician region (15 primary care centers from Ferrol and 17 primary care centers from A Coruña). The study was conducted in accordance with the Declaration of Helsinki and applicable current legislation. In addition, the study was evaluated and approved by the regional committee of the Galician Health Service and all patients gave their written informed consent to use their data in the study.

\section{Patient selection}

This study included male and female patients aged 18 years or older with a documented diagnosis of T2DM who had received treatment with OADs, with or without NPH insulin for at least 8 months, and due to poor glycemic control had been switched to long-acting analogs for at least 5 months before their inclusion in the study. Patients also had to have $\mathrm{HbA1c}$ levels $>8 \%$ before switching to long-acting analog therapy. Patients with concomitant diseases and with a history of severe or repeated asymptomatic hypoglycemic episodes were excluded. Treatment was administered according to standard clinical practice at each study site. Given the observational and retrospective nature of the study, there was no interference in the decision or administration of treatment.

\section{Patient evaluations}

Information on evaluations of the study participants was collected retrospectively from the patients' medical histories at two time points: At the time of the change to therapy with long-acting analogs and after at least 5 months of treatment with long-acting analogs. The information collected at both time points was based on demographic, anthropometric and laboratory test data (HbA1c, blood glucose profile, biochemistry and lipid profile). In addition, data related to antidiabetic treatment (OADs, type of insulin and total daily dose of insulin) was collected at both time points, as well as the number of documented hypoglycemic episodes suffered during the previous month.

Asymptomatic hypoglycemia was defined as an event without symptoms of hypoglycemia but which was associated with a blood glucose value $<3.33 \mathrm{mmol} / \mathrm{L}$. Symptomatic hypoglycemia was defined as an event with symptoms consistent with hypoglycemia in which the subject responded to intake of carbohydrates/food/snack with a blood glucose value $<3.33 \mathrm{mmol} / \mathrm{L}$.

Additionally, the reasons leading to the change in treatment regimen and the assessment of satisfaction with the new treatment perceived by the physician and the patient (very good, good, fair, poor, very poor) after at least 5 months from the treatment change were recorded.

\section{Statistical considerations}

A descriptive analysis was carried out on the study variables using measures of central tendency and dispersion for quantitative variables, and valid frequencies and percentages for qualitative variables. Pre- and post-treatment change comparisons were made using the paired t-test according to the circumstances, Wilcoxon test or Mann-Whitney test for quantitative variables, and the chi-square test, Fisher exact test or McNemar test for qualitative variables. In addition, a multivariate analysis was carried out to obtain a predictive model of the factors associated with the variable "treatment with basal insulin only". Missing data were not imputed and the difference was considered statistically significant if $p \leq 0.05$. All statistical analyses were performed with the Statistical Package for the Social Sciences version 17.0 (SPSS, Inc, Chicago, IL, USA).

\section{Results \\ Patients}

From September 2009 to April 2010, a total of 250 patients 
Soto-González et al. Journal of Diabetes Research \& Clinical Metabolism 2013, http://www.hoajonline.com/journals/pdf/2050-0866-2-20.pdf

Table 2. Previous antidiabetic treatment $(\mathrm{N}=250)$.

\begin{tabular}{lc}
\hline Treatment & Values \\
\hline Oral antidiabetic drugs ${ }^{*}, \mathbf{n}(\%)$ & $\mathbf{2 4 1}(\mathbf{9 6 . 4})$ \\
Metformin & $197(78.8)$ \\
Sulphonylureas & $143(57.2)$ \\
DPP4 Inhibitors & $32(12.8)$ \\
Rapid-acting insulin secretagogues & $22(8.8)$ \\
Thiazolidenediones & $15(6.0)$ \\
Alpha-glucosidase inhibitors & $15(6.0)$ \\
GLP1 analogs & $2(0.8)$ \\
NPH insulin, $\mathbf{n}(\%)$ & $\mathbf{3 8}(\mathbf{1 5 . 2})$ \\
No. NPH insulin injections/day (mean \pm S.D.) & $1.8 \pm 0.4$ \\
Total daily dose of NPH insulin, UI (mean \pm S.D.) & $38.1 \pm 15.8$ \\
Time from treatment initiation with insulin, & $48.5 \pm 47.2$ \\
months (mean \pm S.D.)
\end{tabular}

${ }^{\star}$ Multiple-choice question. DPP4, dipeptidyl peptidase 4; S.D., standard deviation; GLP1, Glucagon-like peptide-1.

were included with the baseline characteristics described in Table 1. The vast majority of these patients (241 (96.4\%)) had been treated with an oral hypoglycemic agent and only 38 (15.2\%) patients had received treatment with NPH insulin before the change in treatment regimen (Table 2).

\section{Anti-diabetic treatment}

After the treatment change, all patients received insulin analogs as basal insulin, consisting of insulin glargine (mean total daily dose, $31.2 \pm 14 \mathrm{IU})$ in 219 (87.6\%) patients and insulin detemir (mean total daily dose, $37.7 \pm 2.5 \mathrm{IU}$ ) in $5(2 \%)$ patients. A total of $223(89.2 \%)$ received only basal insulin as the insulinizing agent, whereas $27(10.8 \%)$ receiving one or more additional doses of rapid insulin: one dose in $4(1.6 \%)$ patients and more than two doses in 23 (9.2\%) patients. On the other hand, treatment with OADs was maintained in 209 (83.6\%) patients: metformin in 177 (84.7\%) patients, sulfonylureas in 32 (15.3\%), DPP-4 antagonists in 23 (11\%), rapid-acting insulin secretagogues in 13 (6.2\%), glitazones in $7(3.3 \%)$, and alpha-glucosidase inhibitors in 4 (1.9\%) patients. The reasons leading to the change in treatment regimen were poor metabolic control in $218(87.2 \%)$ patients, HbA1c levels in 211 (84.4\%), and postprandial glucose levels in 95 (38.0\%) patients. After the first change in treatment regimen, a second change in insulin regimen was made in 95 (39.4\%) patients. Among the reasons given for the change in treatment regimen were poor metabolic control in 52 (54.7\%) patients, HbA1c levels in $43(45.3 \%)$, fasting glucose levels in $40(42.1 \%)$, and postprandial glucose levels in $39(41.1 \%)$ patients.

\section{Efficacy}

On switching to treatment with basal insulin analogs, a reduction was noted in mean $\mathrm{HbA} 1 \mathrm{c}$ levels of $1.6 \%$ during the study, with levels going from $9.2 \pm 1.4 \%$ at the start of therapy with basal insulin analogs to $7.6 \pm 1.1 \%$ after at least

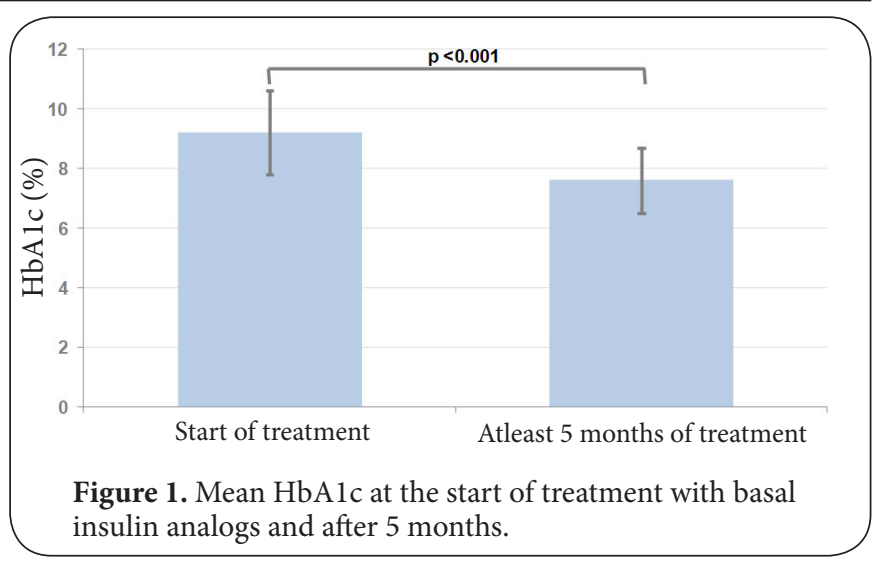

5 months from the treatment change $(p<0.001)$ (Figure 1). Thus, 61 (24.4\%) patients achieved metabolic control (HbA1c levels $<7 \%), 54$ (88.5\%) who had not received NPH insulin before the change in therapy and $7(11.5 \%)$ who had $(p<0.001)$. In this latter subgroup of patients, the mean total daily dose of basal insulin analog was $26.7 \pm 11.7 \mathrm{IU}$, and insulin glargine was the most used basal insulin (56 (91.8\%)). In addition, 49 of 61 (80.3\%) patients with $\mathrm{HbA} 1 \mathrm{c}<7 \%$ were also receiving OADs together with basal insulin: metformin in 41 (83.7\%), sulfonylureas in 7 (14.3\%), DPP-4 antagonists in 7 (14.3\%), rapidacting insulin secretagogues in $3(6.1 \%)$, alpha-glucosidase inhibitors in 2 (4.1\%), and glitazones in 1 (2\%).

Mean fasting blood glucose decreased significantly from the change to therapy with basal insulin analogs to at least 5 months of treatment $(11.1 \pm 3.46 \mathrm{mmol} / \mathrm{L}$ vs $7.6 \pm 2.3 \mathrm{mmol} / \mathrm{L}$; $\mathrm{p}<0.01)$. Similarly, a statistically significant reduction was observed in postprandial blood glucose levels from the start of therapy with basal insulin analogs to at least 5 months of treatment, measured both 2 hours after breakfast $(11.9 \pm 3.2$ $\mathrm{mmol} / \mathrm{L}$ vs $8.8 \pm 2.2 \mathrm{mmol} / \mathrm{L} ; \mathrm{p}<0.01)$, and 2 hours after lunch $(12.4 \pm 3.5 \mathrm{mmol} / \mathrm{L}$ vs $9.6 \pm 2.8 \mathrm{mmol} / \mathrm{L} ; \mathrm{p}<0.01)$ or 2 hours after supper $(11.8 \pm 2.9 \mathrm{mmol} / \mathrm{L}$ vs $9.2 \pm 2.3 \mathrm{mmol} / \mathrm{L} ; \mathrm{p}<0.01)$. Likewise, the same trend was seen on comparing postprandial glucose levels of patients who received treatment with NPH insulin before the change in therapy (Figure 2A) versus those who did not receive it (Figure 2B).

In the 38 patients on NPH insulin before the change in therapy, a significant decrease was seen in the number of patients with hypoglycemic episodes after at least 5 months of treatment with basal insulin analogs versus the start of treatment $(16(42.7 \%)$ vs $5(13.2 \%) ; \mathrm{p}<0.01)$. Although the number of asymptomatic episodes did not vary significantly between both times ( $8(21.1 \%)$ vs $3(7.9 \%) ; p>0.05)$, the number of symptomatic episodes decreased significantly (15 (39.5\%) vs $3(7.0 \%) ; p<0.01$ ) (Table 3 ).

\section{Anthropometric data and cardiovascular risk factors} No statistically significant differences were found in mean patient weight after changing to treatment with basal insulin analogs, which went from $79.8 \pm 13.2 \mathrm{~kg}$ at the start 


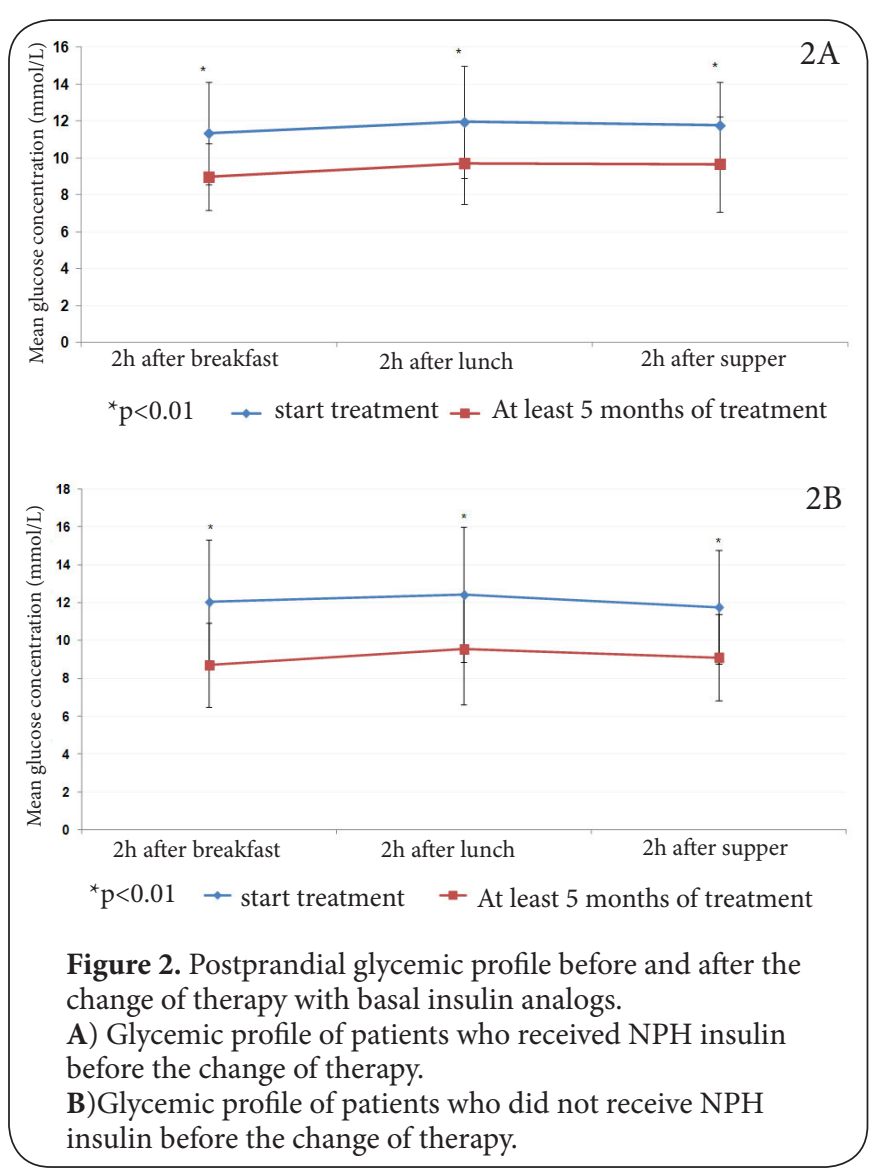

Table 3. Comparison of hypoglycemic episodes before and after treatment with basal insulin analogs $(\mathrm{N}=38)$.

\begin{tabular}{|c|c|c|c|c|}
\hline \multicolumn{5}{|c|}{ Asymptomatic hypoglycaemic episodes, $\mathbf{n}(\%)$} \\
\hline & & \multicolumn{2}{|c|}{ At least 5 months of treatment } & \multirow{2}{*}{ p-value ${ }^{x}$} \\
\hline & & No & Yes & \\
\hline \multirow[b]{2}{*}{ Start of treatment } & No & $28(73.7)$ & $2(5.3)$ & \multirow{2}{*}{$>0.05$} \\
\hline & Yes & $7(18.4)$ & $1(2.6)$ & \\
\hline \multicolumn{5}{|c|}{ Symptomatic hypoglycaemic episodes, n (\%) } \\
\hline & \multicolumn{3}{|c|}{ At least 5 months of treatment } & \multirow{2}{*}{ p-value ${ }^{x}$} \\
\hline & & No & Yes & \\
\hline \multirow[b]{2}{*}{ Start of treatment } & No & $22(57.9)$ & $1(2.6)$ & \multirow[b]{2}{*}{$<0.01$} \\
\hline & & $13(342)$ & $2(53)$ & \\
\hline
\end{tabular}

${ }^{\star}$ McNemar's test for paired data.

of treatment with basal insulin analogs to $79.5 \pm 13.1 \mathrm{~kg}$ after at least 5 months of treatment ( $p>0.05$ ). However, abdominal circumference decreased significantly from $100.9 \pm 14 \mathrm{~cm}$ at the start of treatment to $100.2 \pm 13.6 \mathrm{~cm}$ after at least 5 months of treatment $(p<0.05)$. With regard to cardiovascular risk factors, a statistically significant decrease was also observed in blood pressure values, heart rate and lipid profile from the start of

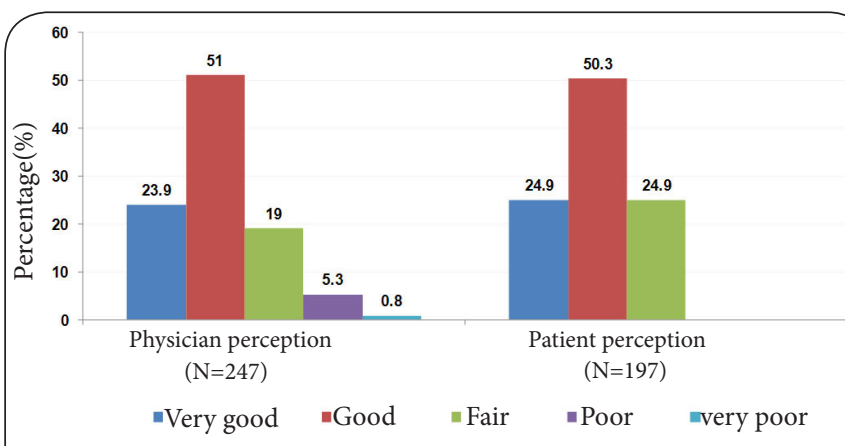

Figure 3. Assessment of treatment satisfaction.

Table 4. Comparison of clinical data $(\mathrm{N}=250)$.

\begin{tabular}{|c|c|c|c|}
\hline & $\begin{array}{l}\text { Start of treatment } \\
(\text { mean } \pm \text { S.D. })\end{array}$ & $\begin{array}{l}\text { At least } 5 \text { months } \\
\text { of treatment } \\
\text { (mean } \pm \text { S.D.) }\end{array}$ & p-value ${ }^{\star}$ \\
\hline $\mathrm{DBP} / \mathrm{SBP}^{\mathrm{a}}, \mathrm{mmHg}$ & $\begin{array}{l}80.3 \pm 8.6 / \\
136.5 \pm 14.9\end{array}$ & $\begin{array}{l}78.6 \pm 8.3 / \\
132.7 \pm 12.9\end{array}$ & $<0.01$ \\
\hline $\mathbf{H R}^{\mathrm{b}}, \mathrm{bpm}$ & $75.4 \pm 7.8$ & $74.2 \pm 7.6$ & $<0.01$ \\
\hline Cholesterol $^{\mathrm{c}},(\mathrm{mmol} / \mathrm{l})$ & $5.1 \pm 1$ & $4.8 \pm 0.9$ & $<0.01$ \\
\hline $\mathbf{L D L}^{\mathbf{d}}(\mathrm{mmol} / \mathrm{l})$ & $2.9 \pm 0.9$ & $2.7 \pm 0.8$ & $<0.01$ \\
\hline $\mathrm{HDL}^{\mathrm{e}}(\mathrm{mmol} / \mathrm{l})$ & $1.4 \pm 0.4$ & $1.4 \pm 0.5$ & $>0.05$ \\
\hline Triglycerides $^{\mathrm{f}}(\mathrm{mmol} / \mathrm{l})$ & $4.3 \pm 2.8$ & $3.7 \pm 1.9$ & $<0.01$ \\
\hline
\end{tabular}

Missing data, ${ }^{a} \mathrm{n}=4,{ }^{\mathrm{b}} \mathrm{n}=25,{ }^{\mathrm{c}} \mathrm{n}=5,{ }^{\mathrm{d}} \mathrm{n}=33,{ }^{\mathrm{e}} \mathrm{n}=34,{ }^{\mathrm{f}} \mathrm{n}=17$.

*T-test, DBP, diastolic blood pressure; SBP, systolic blood pressure; HR, heart rate; S.D., standard deviation.

treatment with basal insulin analogs to at least 5 months of treatment $(p<0.01)$ (Table 4).

\section{Treatment satisfaction}

The assessment of patient treatment satisfaction perceived by the physician revealed that in $185(74.9 \%)$ patients, this was considered to be "good/very good", "fair" in 47 (19\%), and "poor/very poor" in 15 (6.1\%) patients. Regarding the patient perception of treatment satisfaction, $148(75.2 \%)$ patients rated their satisfaction as "good/very good" and 49 (24.8\%) as "fair" (Figure 3).

\section{Discussion}

This study was designed as a retrospective observational study to determine if therapy with long-acting basal insulin analogs in combination with OADs improves glycemic control, measured in terms of reduction of $\mathrm{HbA1c}$ levels and hypoglycemic episodes in patients with T2DM, who despite receiving oral hypoglycemic agents in combination or not with NPH insulin had poor metabolic control ( $\mathrm{HbA1c}>8 \%$ ). Numerous studies have investigated the benefits of adding long-acting basal insulin analogs, specifically insulin glargine, to oral hypoglycemic treatment in comparison to NPH insulin in patients with T2DM and poor glycemic control [11,15-17]. Although, in general, both regimens have been shown to be 
effective in controlling blood glucose levels, treatments based on administration of insulin glargine appear to achieve target $\mathrm{HbA} 1 \mathrm{c}$ levels with a lower incidence of hypoglycemic episodes and to have greater effectiveness in metabolic control in these patients. Thus, the results obtained in the investigation carried out by MC Riddle et al., showed that the addition of insulin glargine or NPH insulin to treatment with oral hypoglycemic agents to achieve $\mathrm{HbA} 1 \mathrm{c}$ levels $<7 \%$, resulted in both groups in a decrease of $1.6 \%$ in $\mathrm{HbA1c}$ levels [11]. This reduction in $\mathrm{HbA} 1 \mathrm{c}$ levels is comparable to that found in our study, confirming the beneficial effect of adding long-acting basal insulin analogs to treatment with oral hypoglycemic agents for glycemic control in patients with T2DM and poor glycemic control under routine clinical practice conditions. Furthermore, it was seen that a larger proportion of patients treated with insulin glargine obtained these results without the occurrence of nocturnal hypoglycemic episodes [11]. Similarly, an open study carried out in 29 European sites to compare the efficacy and safety of both formulations noted that there was a significantly higher number of patients in the NPH insulin group that suffered a nocturnal hypoglycemic episode than in the insulin glargine group [15]. However, our investigation could not establish a comparison in the incidence of nocturnal hypoglycemic episodes between both therapies because of the small number of patients initially in the NPH insulin group, and furthermore the study was about basal insulin analogs and not only insulin glargine. Nevertheless, our investigation obtained a reduction in the number of hypoglycemic episodes, mainly symptomatic, after the change in treatment. These results are comparable to those obtained in the study conducted by Yki-Järvinen et al., in which it was found that control of blood glucose levels could be achieved after the addition of insulin glargine or NPH insulin to hypoglycemic treatment with metformin. However, a larger number of patients in the group treated with NPH insulin suffered a symptomatic hypoglycemic event as compared to patients who received insulin glargine [17].

The importance of maintaining strict control of blood glucose levels by achieving target $\mathrm{HbA} 1 \mathrm{c}$ values with the aim of reducing microvascular and macrovascular complications in patients with T2DM is widely known. Thus, a $1 \%$ reduction in $\mathrm{HbA} 1 \mathrm{c}$ levels is associated with a $14 \%$ reduction in the risk of suffering a myocardial infarction and in mortality for any cause, a $37 \%$ reduction in microvascular complications and a $21 \%$ reduction in overall complications of diabetes [4]. A recently published observational study noted that the addition of insulin to existing treatment with OADs did not significantly increase the incidence of microvascular and macrovascular events in comparison to the addition of a new OAD to existing treatment [18].

Furthermore, it is know that $\mathrm{HbA} 1 \mathrm{c}$ reflects the contribution of both fasting hyperglycemia or basal hyperglycemia (BHG) and postprandial hyperglycemia (PPHG). In our study, the reduction in $\mathrm{HbA} 1 \mathrm{c}$ levels could be largely due to the reduction in fasting hyperglycemia levels, since this reduction was higher in those patients who did not receive $\mathrm{NPH}$ insulin than in those who did. The relative contribution of $\mathrm{BHG}$ and PPHG to $\mathrm{HbA1c}$ levels have been shown in recent study carried out by M Riddle et al., this study noted that in patients with $\mathrm{HbA} 1 \mathrm{c}>7 \%$, BHG was the contribution that initially predominates in $\mathrm{HbA} 1 \mathrm{c}$ results in a proportion of almost $80 \%$ depending on the $\mathrm{HbA} 1 \mathrm{c}$ level, despite treatment with OADs. Following treatment intensification, it has been seen that this contribution decreases to $34 \%$ after treatment with basal insulin, or nearly $70 \%$ after administration of other therapeutic agents [19]. These results, therefore, expand the concept that L Monnier et al., proposed and developed in two consecutive studies, showing that intensification of hypoglycemiant treatment modifies the relative contribution of BHG versus PPHG on $\mathrm{HbA1}$ c values [20,21].

The authors recognize some limitations in this study that should be considered when interpreting its results. First, insulin glargine was found to be the basal insulin analog administered to most of the study participants, so it would be difficult to ensure that similar results would be obtained with other basal insulin analogs. Furthermore, the design of our investigation was proposed only as a short duration study, so its results cannot be used to infer long-term effectiveness. Finally, as it is an observational study, the information extracted does not provide sufficient evidence to establish cause-effect relationships. However, the conducting of this type of studies is of great relevance to know the conditions derived from routine clinical practice.

\section{Conclusions}

The results obtained in this study show that treatment with long-acting basal insulin analogs improved glycemic control in T2DM patients poorly controlled with OADs in combination or not with NPH insulin, under routine clinical practice conditions. Moreover, this improvement was produced with a significant reduction in the number of symptomatic hypoglycemic episodes and without a significant increase in body weight of the participating patients.

\section{List of abbreviations}

BHG: Basal hyperglycemia

HbA1c: Glycated hemoglobin

OADs: Oral antidiabetic drugs

PPHG: Postprandial hyperglycemia

T2DM: Type 2 diabetes mellitus

\section{Competing interests}

The authors declare that they have no competing interests.

\section{Authors' contributions}

All authors took part in the conception and design of the study; analysis and interpretation of data; drafting of the article or revising it critically for important intellectual content and final approval of the version to be published.

\section{Acknowledgement}

The authors thank all of the Investigators of the BALADO 
Soto-González et al. Journal of Diabetes Research \& Clinical Metabolism 2013, http://www.hoajonline.com/journals/pdf/2050-0866-2-20.pdf

doi: $10.7243 / 2050-0866-2-20$

Study Group for its dedication and enthusiasm. We thank Ana López and Antonio Torres (Dynamic S.L.) for assistance in medical writing and editing, funded by Sanofi Spain. This study was sponsored by Sanofi Spain. BALADO Study Group: Ma C Duran, Marcelino, Carlos Sueiras, Margarita Palacios, Ma Cruz Grandal, Manuel A Ramos, Miguel De Santiago, Fernando Malo, Cayetano Galan, Jose C. Garcia Vilamea, Cristina Iglesias, Manuel Pereira, Jesus De Juan, Carlos Castiñeira, Esperanza Rodriguez Moldes, Fernando Paramio, Francisco Malvar, Juan R. Couce, Manuel Tarrio, Juan Martinez Montero, Eloy Gonzalez Alonso, Adolfo Rodriguez Teijeiro, Jose Cabello, Juan Francisco Sanchez Perez, $M^{a}$ Luisa Varela, Dolores Recarey, $\mathrm{M}^{\text {a }}$ Portal, Jose Insua, Andres Martinez Gonzalez, Jose Ignacio Paz, Antonio Jose Asensi, Ma Lopez Toledo, Luis Seoane, Ma C Pastor, Ma Luisa Marin, Luis M Fernandez Alonso, Manuel Barral, Alejandra Rey, Ma Mar Terceiro, Juan Manuel Peteiro, $M^{a}$ Antonia Trueba, Mercedes Ferreira, Ana I Carvajal, Ma Asuncion Lijo, Ma Luisa Zapata, Manuel Soto, Lidia Vazquez., Jose Carreira, Arturo Salvande.

Publication history

Received: 04-Feb-2013 Revised: 10-Apr-2013

Accepted: 26-Apr-2013 Published: 04-May-2013

\section{References}

1. Menendez Torre E, Lafita Tejedor FJ, Artola Menendez S, Millan Nunez-Cortes J, Alonso Garcia A, Puig Domingo M, Garcia Solans JR, Alvarez Guisasola F, Garcia Alegria J, Mediavilla Bravo J, Miranda Fernandez-Santos $\mathrm{C}$ and Romero Gonzalez R: [Recommendations for the pharmacological treatment of hyperglycemia in type 2 diabetes]. Aten Primaria 2011, 43:202 e1-9. | Article | PubMed

2. Standards of medical care in diabetes--2011. Diabetes Care 2011, 34 Suppl 1:S11-61. | Article | PubMed Abstract | PubMed Full Text

3. Nathan DM, Buse JB, Davidson MB, Ferrannini E, Holman RR, Sherwin $R$ and Zinman $B$ : Medical management of hyperglycemia in type 2 diabetes: a consensus algorithm for the initiation and adjustment of therapy: a consensus statement of the American Diabetes Association and the European Association for the Study of Diabetes. Diabetes Care 2009, 32:193-203. | Article | PubMed Abstract | PubMed Full Text

4. Stratton IM, Adler AI, Neil HA, Matthews DR, Manley SE, Cull CA, Hadden D, Turner RC and Holman RR: Association of glycaemia with macrovascular and microvascular complications of type $\mathbf{2}$ diabetes (UKPDS 35): prospective observational study. BMJ 2000, 321:405-12. Article | PubMed Abstract | PubMed Full Text

5. Effect of intensive blood-glucose control with metformin on complications in overweight patients with type 2 diabetes (UKPDS 34). UK Prospective Diabetes Study (UKPDS) Group. Lancet 1998, 352:85465. | Article | PubMed

6. Intensive blood-glucose control with sulphonylureas or insulin compared with conventional treatment and risk of complications in patients with type 2 diabetes (UKPDS 33). UK Prospective Diabetes Study (UKPDS) Group. Lancet 1998, 352:837-53. | Article I PubMed

7. Turner RC, Cull CA, Frighi V and Holman RR: Glycemic control with diet, sulfonylurea, metformin, or insulin in patients with type 2 diabetes mellitus: progressive requirement for multiple therapies (UKPDS 49). UK Prospective Diabetes Study (UKPDS) Group. JAMA 1999, 281:200512. | Article | PubMed

8. Bretzel RG, Nuber U, Landgraf W, Owens DR, Bradley C and Linn T: Oncedaily basal insulin glargine versus thrice-daily prandial insulin lispro in people with type $\mathbf{2}$ diabetes on oral hypoglycaemic agents (APOLLO): an open randomised controlled trial. Lancet 2008, 371:1073-84. | Article | PubMed

9. Gerstein HC, Yale JF, Harris SB, Issa M, Stewart JA and Dempsey E: A randomized trial of adding insulin glargine vs. avoidance of insulin in people with Type $\mathbf{2}$ diabetes on either no oral glucose-lowering agents or submaximal doses of metformin and/or sulphonylureas. The Canadian INSIGHT (Implementing New Strategies with Insulin Glargine for Hyperglycaemia Treatment) Study. Diabet Med 2006, 23:736-42. Article I PubMed

10. Hermansen K, Davies M, Derezinski T, Martinez Ravn G, Clauson P and Home P: A 26-week, randomized, parallel, treat-to-target trial comparing insulin detemir with NPH insulin as add-on therapy to oral glucose-lowering drugs in insulin-naive people with type 2 diabetes. Diabetes Care 2006, 29:1269-74. | Article | PubMed

11. Riddle MC, Rosenstock J and Gerich J: The treat-to-target trial: randomized addition of glargine or human NPH insulin to oral therapy of type 2 diabetic patients. Diabetes Care 2003, 26:3080-6. | Article | PubMed

12. Yki-Jarvinen $H$, Juurinen $L$, Alvarsson $M$, Bystedt $T$, Caldwell I, Davies $M$, Lahdenpera S, Nijpels $\mathrm{G}$ and Vahatalo M: Initiate Insulin by Aggressive Titration and Education (INITIATE): a randomized study to compare initiation of insulin combination therapy in type $\mathbf{2}$ diabetic patients individually and in groups. Diabetes Care 2007, 30:1364-9. | Article | PubMed

13. Hayward RA, Manning WG, Kaplan SH, Wagner EH and Greenfield S: Starting insulin therapy in patients with type 2 diabetes: effectiveness, complications, and resource utilization. JAMA 1997, 278:1663-9. | Article | PubMed

14. Cryer PE: Hypoglycemia is the limiting factor in the management of diabetes. Diabetes Metab Res Rev 1999, 15:42-6. I Article I PubMed

15. Safety and efficacy of insulin glargine (HOE 901) versus NPH insulin in combination with oral treatment in Type 2 diabetic patients. Diabet Med 2003, 20:545-51. | Article | PubMed

16. Eliaschewitz FG, Calvo C, Valbuena H, Ruiz M, Aschner P, Villena J, Ramirez LA and Jimenez J: Therapy in type 2 diabetes: insulin glargine vs. NPH insulin both in combination with glimepiride. Arch Med Res 2006, 37:495-501. | Article | PubMed

17. Yki-Jarvinen $\mathrm{H}$, Kauppinen-Makelin $\mathrm{R}$, Tiikkainen $\mathrm{M}$, Vahatalo $\mathrm{M}$, Virtamo H, Nikkila K, Tulokas T, Hulme S, Hardy K, McNulty S, Hanninen J, Levanen H, Lahdenpera S, Lehtonen R and Ryysy L: Insulin glargine or NPH combined with metformin in type 2 diabetes: the LANMET study. Diabetologia 2006, 49:442-51. | Article | PubMed

18. Hall GC, McMahon AD, Carroll D and Home PD: Macrovascular and microvascular outcomes after beginning of insulin versus additional oral glucose-lowering therapy in people with type $\mathbf{2}$ diabetes: an observational study. Pharmacoepidemiol Drug Saf 2012, 21:305-13. | Article | PubMed

19. Riddle M, Umpierrez G, DiGenio A, Zhou R and Rosenstock J: Contributions of basal and postprandial hyperglycemia over a wide range of A1C levels before and after treatment intensification in type $\mathbf{2}$ diabetes. Diabetes Care 2011, 34:2508-14. | Article | PubMed Abstract | PubMed Full Text

20. Monnier L, Lapinski $\mathrm{H}$ and Colette $\mathrm{C}$ : Contributions of fasting and postprandial plasma glucose increments to the overall diurnal hyperglycemia of type $\mathbf{2}$ diabetic patients: variations with increasing levels of $\mathrm{HbA}(\mathbf{1 c})$. Diabetes Care 2003, 26:881-5. | Article | PubMed

21. Monnier L, Colette C, Dunseath GJ and Owens DR: The loss of postprandial glycemic control precedes stepwise deterioration of fasting with worsening diabetes. Diabetes Care 2007, 30:263-9. | Article | PubMed

\section{Citation:}

Soto-González A and Bellido-Guerrero D: Effectiveness of therapy with basal insulin analogs to improve glycemic control in type 2 diabetes mellitus patients poorly controlled with oral antidiabetic drugs in combination or not with NPH insulin. Journal of Diabetes Research \& Clinical Metabolism 2013, 2:20. http://dx.doi.org/10.7243/2050-0866-2-20 